\title{
Aspects of the production of planting material from lignified cuttings using frameless film microcoats
}

\author{
M. A. Mekhedov ${ }^{1,2}, R . A$. Filippov ${ }^{3, *}, A$. A. Tsymbal ${ }^{1,2}$, and I. I. Chukhlyaev ${ }^{3}$ \\ ${ }^{1}$ IME named after V.P.Goryachkin, Moscow, Russia \\ ${ }^{2}$ Russian State Agrarian University- Moscow Agricultural Academy named after K.A. Timiryazev, \\ Moscow, Russia \\ ${ }^{3}$ Federal Scientific Agroengineering Center VIM, 1-st Institutsky proezd, 5, Moscow, 109428, Russia.
}

\begin{abstract}
The article contains the results of the completed stage of researches on the evaluation of the effectiveness and justification of the use of frameless ground film coatings with the formation of local microgreenhouse cavities.
\end{abstract}

One of the most common and popular methods of vegetative way of obtaining planting material of black currant, grape, sea - buckthorn and a number of others (fruit, berry, ornamental) crops with full preservation of their varietal, technological and consumer characteristics is the rooting of lignified cuttings. Having a number of undeniable advantages (especially at the initial stage), propagation with cuttings still remains technologically diverse, technically complex, time-consuming in the thoroughness of execution and expensive at the initial stage of the process.

Well-known technologies of the production of seedlings from cuttings, although they provide for multiple mechanized operations of the care of plantings in the nursery (for example, for currants there are more than 20 of them), however, they do not exclude:

- unavoidable labor-intensive manual weeding in plant rows [1];

- the need of herbicides application;

- rapid drying of the upper soil layer, where the main part of seedlings roots is concentrated [1].

Often, even if all the requirements of agricultural technology are met, these technologies do not guarantee the production of seedlings in one year that are completely ready for laying their commercial plantings and (or) for sale to other consumers.

It forces us either to leave or replant substandard plants for re-growing in the next year, which in any case significantly reduces the economic parameters of production. Thus, the total labor costs for weeding and loosening the soil in rows when growing currant seedlings from cuttings with a planting scheme of $70 \times 7 \mathrm{~cm}$ reach 230 people-hours/ha, which is more than $10 \%$ of the total cost of manual labor in the technology.

On the basis of SSI VSTISP of the Russian Agricultural Academy, a method of growing

\footnotetext{
* Corresponding author: rostislav-filippov@yandex.ru
} 
seedlings by rooting lignified cuttings with planting them in a frameless film micro-coating was developed and tested in the field in 2004-2005, and subsequently patented [2, 3, 4].

In laboratory and field experiments, the cultivation of currant seedlings from cuttings was compared:

- traditional method as a control (Fig. 1A);

- and two technology options of pre-continuous mulching by the opaque film, namely:

- contact cover of the entire soil surface in the area of the planted cuttings (Fig. 1B);

- with the formation on the soil surface under the film micro-greenhouse cavity along the entire length of the row (Fig.1B).

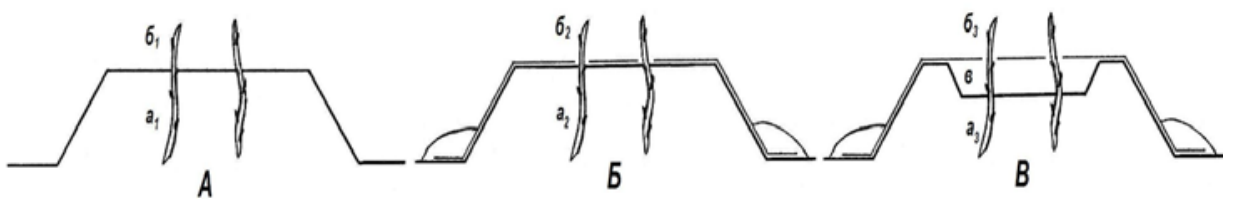

Fig. 1. Options of growing seedlings from cuttings: A-open ground (control); B-film mulching of the row surface; C-film mulching with a micro-thermal cavity; a - rooted zone; b - the area where the aboveground part of the cuttings is located; $\mathrm{c}$ - the area where the cuttings are located in the microthermal cavity.

According to the first experimental version (Fig. 1B) of mulching (tight fit of the film to the soil surface), the coating is designed to suppress the growth of weeds and actually successfully provides it. In the second experimental version (with the formation of a frameless cover, Fig. 1B) in addition to the anti-weed effect, a local active zone is created for the formation of micro-thermal conditions for several buds in the ground part of cuttings, which accelerates the development of a seedling and stimulates root formation, and, consequently, reduces the percentage of rejection of seedlings obtained in the nursery after the first year of cultivation.

The ranking on the quality and degree of influence of the parameters indicated above in the three cultivation options on the intensity of development of seedlings from cuttings conducted by a group of specialists can be represented as the ratio of technological preference (significance) of selected range of cuttings according to the options.

In the course of the field testing, work even with such an easily rooted crop as black currant, often not even requiring additional stimulation:

- confirmed that the creation of a frameless micro-thermal cover made of a polymer film significantly improves root formation, growth activity and subsequent development of seedlings at a statistically significant level;

- allowed us to develop a schematic diagram of the unit with the justification of its design and technological parameters for mechanized preparation of the ridge surface, which ensures the formation of soil micro-cover [2];

- emphasized the advantages of the proposed method of soil mulching in the cuttings school in the implementation of multi-line tape planting methods [5]: reducing the number of passes of equipment in the field during care; the possibility of obtaining up to $85 \%$ of seedlings of the first grade per year (even without irrigation) (which is 2-4 times more than in the control - open cuttings nursery) from $65-75 \%$ of the number of cuttings planted.

As a result, the variant under the letter B in the aggregate exceeds the variants B and A. (Table 1).

Table 1. Comparison of currant cuttings methods

\begin{tabular}{|c|c|c|}
\hline Rating parameter & Ratio in the group & Priority \\
\hline Root formation & $a_{3}>a_{2}>a_{1}$ & $V$ \\
\hline Stem growth & $\left(b_{2} \square b_{3}\right) \square b_{1}$ & $V$ and $B$ \\
\hline Growth activity & $\left(a_{3}+b_{3}+v\right) \square \square\left(a_{2}+b_{2}\right) \square\left(a_{1}+b_{1}\right)$ & $V$ \\
\hline
\end{tabular}


The method involves the sequential mechanized execution of the following operations:

a) preparation of the planting bed with the formation of a depression not less than the average double distance between the buds on the cuttings of the selected variety;

b) the layout on the bottom of the recess of the humidifier selected for the irrigation method (if necessary);

c) spreading the covering cloth on the bed, perforated (simultaneously with the laying of the cloth) with cuts of no more than $30 \mathrm{~mm}$ according to the planting scheme;

d) soil sprinkling of the edges of the mulch web and compaction.

Planting cuttings on the ridge should be carried out in increments of $7.5 \mathrm{~cm}$ in the tape, in a staggered order, consisting of two lines, with a distance between them of $20 \mathrm{~cm}$, to a depth of $10 \ldots 15 \mathrm{~cm}$, leaving one or two buds above the film.

The evaluation of the technological features of the proposed method was carried out in a comprehensive manner based on the totality of current parameters in the ranges of their changes according to the method of constructing working hypotheses of researches.

The soil temperature and the surface layer of air. In relation to the temperature diurnal cycles, the analysis of the dynamics of soil temperature showed that the frameless microcover has a stabilizing effect on the soil temperature, preventing sudden cooling (for example, during short-term frosts) and overheating during sunny summer days.

Soil moisture. Observations of changes in soil moisture have established that frameless micro-coating prevents unproductive evaporation from the surface. It also helps to maintain soil moisture even on a non-irrigated background in layers 0-10 and 10-20 not lower than the optimum (70-80 \% PV). As already noted, it is especially important for the cuttings nursery, where the bulk of the roots are located in the upper layers of the soil. Thus, frameless micro-covering in a favorable humidification year in 2004 provided an increase in absolute soil moisture in the $0-20 \mathrm{~cm}$ layer by $4.5 \%$ compared to open soil and in the dry summer-autumn period of 2005 by 13\%. When mulching without a cavity, the indicated humidity increases were slightly lower - 1.2...1.4 and 6...11\%, respectively.

The effectiveness of additional irrigation was not evaluated, as the need for it did not arise in the years of field experiments.

Soil density. The soil density under the mulch and micro-coating remained at the level of $1.02 \ldots 1.06 \mathrm{~g} / \mathrm{cm}^{3}$, which corresponds to a loose state for the sod-podzolic mediumloamy soil of the experimental site, and it is favorable for the development of the root system of seedlings. The crust present in the control and provoking intensive desiccation of the upper layers of the soil was not formed under the mulch, the fine-lumpy aggregate composition created by mechanical processing before the formation of the micro-coating was preserved.

Weed vegetation. Quantitative accounting of weed vegetation showed that mulching with a light-transparent plastic film, both with and without an air cavity, effectively inhibits weed vegetation. Frameless micro-covering most effectively restrains the development of weeds. Because of clogging in the control (open soil), reaching $417 \mathrm{pcs} / \mathrm{m}^{2}$, when using a film light-proof mulch with a 30 -millimeter perforation for planting cuttings, the number of weeds per $1 \mathrm{~m}^{2}$ for two-line planting according to the scheme $120+20 \times 7.5 \mathrm{~cm}$, the weed infestation of the ridge decreased by 17 times. Under the film, the stable death of the most active perennial weeds (field sedge, creeping wheatgrass, large plantain) was recorded. Thus, micro-coating allows you to clean the soil from weeds without the use of herbicides and multiple mechanical treatments.

The seedling yield was recorded according to the biometric quality parameters established by the industry standard OST 10 206-97. Mulching and open soil provided the yield of blackcurrant seedlings in the range of $67 \ldots 93 \%$, frameless micro-covering $64 . . .46 \%$. 
However, it should be noted that with a high yield, the parameters of commercial quality of seedlings in open soil are the lowest.

Mulching in comparison with the control contributed to an increase in:

- the length of the branched root system by 11 ... $57 \%$;

- shoot lengths by $47 . . .124 \%$;

- the diameter of the base of the shoots by 25 ... $36 \%$.

With frameless micro-covering, the increases in these parameters were maximal and equal, respectively - 39...69; 92...139; 32...33 \%.

The use of frameless micro-coating and mulching according to the results of two years in comparison with the control consistently increased the commercial grade of the resulting planting material. At the same time, the tendency to reduce non - standard seedlings (by 35 and $30 \%$, respectively) and to increase the share of seedlings of the1st grade (by 51 and $38 \%$ ) was most pronounced, while the share of the 2nd grade decreased at least by 16 and 8 $\%$ [5].

The economic calculation showed that the cost of seedlings in cultivation using microcovering and in open soil are close, but due to the different quality of the seedlings obtained, the level of profitability in the first case is $20 \%$ higher and is equal to $275 \%$. The necessary capital investments for the production of a micro-coating preparation unit (at the cost of foreign ridge-forming mulch-laying machines of similar design) will pay off in one year, based on the area of the black currant cuttings mini-nursery with the adopted planting scheme of 0.14 hectares, which indicates a high investment efficiency, even with a small production volume of seedlings. At the same time, it is possible to use the unit in cuttings of other crops (grapes, sea buckthorn, clonal rootstocks of ornamental trees and shrubs, and others), which will increase the efficiency of investment.

\section{References}

1. Skalii L. P. Reproduction of black currant by lignified cuttings with the use of synthetic films. / L. P. Skalii // TAA reports. 1978, - Issue 246. - p. 23-28.

2. Mekhedov M.A. Frameless micro-coating for rooting lignified cuttings // Achievements of science and technology of the agro-industrial complex - 2005. - № 9. - P.16-17.

3. Patent for invention № 2286665 Russian Federation, MPK A01G1/00. Method of laying a cuttings mini-nursery / M.A. Mekhedov, V.I. Paliev, A.A. Tsymbal; claimant and patent holder SSI VSTISP Russian Agricultural Academy №2005110916/12; claimant 15.04.2005; published 10.11.2006. Bul. № 31. - 7 p.

4. Patent for invention № 2283556 Russian Federation, MPK A01B13/02, A01B49/02, F01C7/00. Unit for laying a perforated film on a ridge of a given profile / M.A. Mekhedov, V.I. Paliev, A.A. Tsymbal; claimant and patent holder SSI VSTISP Russian Agricultural Academy №2005102609/12; claimed 03.02.2005; published 20.09.2006. Bul. № 26. -9 p.

5. Mekhedov M.A. Rooting of lignified cuttings in the frameless micro-coating (article). / M.A. Mekhedov, A.A. Tsymbal // TAA reports. 2011, Issue 283, Part 1, M.: Publisher RSAU-MAA. 2011. P. 800-804. 